\title{
Topography and Lateralized Effect of Acute Aromatase Inhibition on Auditory Processing in a Seasonal Songbird
}

\author{
Geert De Groof, ${ }^{1}$-Jacques Balthazart, ${ }^{-}$Charlotte A. Cornil, ${ }^{2}$ and Annemie Van der Linden ${ }^{1}$ \\ ${ }^{1}$ Bio-Imaging Laboratory, University of Antwerp, CDE, Universiteitsplein 1, B-2610 Antwerp, Belgium, and ${ }^{2}$ Research Group in Behavioral \\ Neuroendocrinology, GIGA Neurosciences, University of Liège, B-4000 Liège, Belgium
}

It is increasingly recognized that brain-derived estrogens (neuroestrogens) can regulate brain physiology and behavior much faster than what was previously known from the transcriptional action of estrogens on nuclear receptors. One of the best examples of such neuromodulation by neuroestrogens concerns the acute regulation of sensory coding by the auditory cortex as demonstrated by electrophysiological studies of selected neurons in zebra finches. Yet, the spatial extent of such modulation by neuroestrogens is not known. Using functional magnetic resonance imaging, we demonstrate here that acute estrogen depletion alters within minutes auditory processing in male European starlings. These effects are confined to very specific but large areas of the auditory cortex. They are also specifically lateralized to the left hemisphere. Interestingly, the modulation of auditory responses by estrogens was much larger (both in amplitude and in topography) in March than in December or May/June. This effect was presumably independent from changes in circulating testosterone concentrations since levels of the steroid were controlled by subcutaneous implants, thus suggesting actions related to other aspects of the seasonal cycle or photoperiodic manipulations. Finally, we also show that estrogen production specifically modulates selectivity for behaviorally relevant vocalizations in a specific part of the caudomedial nidopallium. These findings confirm and extend previous conclusions that had been obtained by electrophysiological techniques. This approach provides a new very powerful tool to investigate auditory responsiveness in songbirds and its fast modulation by sex steroids.

Key words: European starling; fMRI; lateralization; NCM; rapid estrogen action

Significance Statement

Neuroestrogens can acutely modulate sensory processing in a manner similar to neuromodulators. We report that acute estrogen depletion rapidly disrupts auditory processing in large areas of the male starling brain. Effects were larger in March than in December or May/June, lateralized to the left hemisphere and specific to behaviorally relevant stimuli. These findings confirm and extend previous data that identified an acute regulation of auditory neurons in zebra finches by (1) delineating the extent of the brain region affected, (2) confirming its lateralization, and (3) demonstrating that a large part of the auditory brain regions are acutely affected by estrogens. These findings provide a very powerful tool to investigate auditory responsiveness in songbirds and its fast modulation by sex steroids.

\section{Introduction}

Estrogens affect multiple reproductive traits but also nonreproductive traits, such as cognition. Although usually associated with long-term changes in physiological state mediated by steroidinduced modifications in gene transcription (Etgen and Pfaff,

\footnotetext{
Received June 20, 2016; revised Jan. 27, 2017; accepted Feb. 23, 2017.

Author contributions: G.D.G., J.B., and C.A.C. designed research; G.D.G. and C.A.C. performed research; J.B., C.A.C., and A.V.d.L. contributed unpublished reagents/analytic tools; G.D.G. and C.A.C. analyzed data; G.D.G., J.B., and C.A.C. wrote the paper.

This work was supported by grants from the Research Foundation-Flanders (FWO, projects $\mathrm{Nr}$ G042002 and G044311N), the Hercules Foundation (Grant Nr AUHA0012), Concerted Research Actions (GOA funding) from the University of Antwerp to A.VdL., and the Interuniversity Attraction Poles (IAP; PLASTOCINE: P7/17) to A.VdL., J.B., and C.A.C. C.A.C. is a F.R.S.-FNRS Research Associate and G.DG is a Postdoctoral Fellow of the Research FoundationFlanders (FWO). We thank Isabelle George and Martine Hausberger for providing the birds and the song stimuli for this experiment.
}

2010), estrogens also affect brain activity with much shorter latencies in the order of minutes or seconds (Maggi et al., 2004; Kelly and Ronnekleiv, 2009). In animal models ranging from fishes to mammals, these changes in neuronal activity induce rapid (within minutes) behavioral effects that are thus probably too fast to be mediated by the transcriptional activity of the steroid (Cornil et al., 2012). In parallel it has recently been shown that brain estrogen synthesis is regulated within minutes by neuronal activity (Saldanha et al., 2011; Cornil et al., 2012). This

Correspondence should be addressed to Prof. Dr. Annemie Van der Linden, Bio-Imaging Laboratory, University of Antwerp, CDE, Universiteitsplein 1, B-2610 Antwerp, Belgium. E-mail: annemie.vanderlinden@uantwerp.be. DOl:10.1523/JNEUROSCI.1961-16.2017

Copyright $\odot 2017$ the authors $\quad 0270-6474 / 17 / 374243-12 \$ 15.00 / 0$ 
provides a mechanism generating the rapid fluctuations in brain estrogen concentrations that are presumably needed to control rapid changes in behavior (Cornil et al., 2006a).

$17 \beta$-Estradiol (E2) is an important neuromodulator of auditory processing in many vertebrates including vocal learners such as humans and songbirds (Caras, 2013; Remage-Healey, 2014). Multiple evidence supports this neuromodulatory function of E2 in zebra finches, Taeniopygia guttata (Remage-Healey et al., 2013). First, estrogen concentrations as measured by in vivo microdialysis fluctuate rapidly in the auditory cortex of males and females who interact with or listen to conspecifics (RemageHealey et al., 2008, 2012). Second, exogenous estrogens rapidly enhance auditory-evoked neuronal activity in the same auditory areas and in turn enhance auditory processing (Tremere et al., 2009; Remage-Healey et al., 2010, 2012). Third, acute blockade of estrogen synthesis in these regions decreases auditory neuronal responsiveness and behavioral preferences for specific songs (Remage-Healey et al., 2010; Tremere and Pinaud, 2011). Finally in the auditory cortex estrogens transsynaptically affect the sensorimotor circuits, including nucleus HVC, and enhance neural representations of songs (Remage-Healey and Joshi, 2012).

We previously showed, using functional magnetic resonance imaging (fMRI), that processing of conspecific songs in the caudomedial nidopallium (NCM) of male European starlings (Sturnus vulgaris) significantly differs in breeding and nonbreeding seasons (De Groof et al., 2013). Because breeding and nonbreeding songbirds are exposed to extremely different concentrations of testosterone (T) and its brain metabolite E2 (Fusani et al., 2000; Riters et al., 2001; Soma et al., 2003) and because E2 rapidly modulates neuronal activity in the auditory cortex of zebra finches (see above), we wondered whether depleting brain estrogens (by acute aromatase blockade) would affect auditory processing in large brain regions visualized by fMRI as suggested by the electrophysiological effects detected in a selected set of neurons (Remage-Healey et al., 2010; Tremere and Pinaud, 2011).

Because the rapid behavioral effects of 2 can be modulated by the photoperiod (in California mice, Peromyscus californicus; Trainor et al., 2008) and by seasons (in a songbird, the song sparrow, Melospiza melodia; Heimovics et al., 2012, 2015), separate $\mathrm{fMRI}$ imaging sessions testing acute effects of estrogen depletion were performed in December ( $8 \mathrm{~h}$ light/16 h dark cycle), in early March ( $11 \mathrm{~h}$ light/13 h dark) and again in May/June (16 h light $/ 8 \mathrm{~h}$ dark). To test the effect of changes in photoperiod independently of changes in circulating $\mathrm{T}$, males were chronically treated with $\mathrm{T}$ for 3 weeks before each imaging session. In each case, brain auditory responses were measured in response to the presentation of songs conveying species-specific (SPEC songs) or individual information (INDIV songs) or to synthetic pure tones (PT) first during a control session and then $10 \mathrm{~min}$ after an injection of the potent aromatase inhibitor vorozole (VOR). To test whether VOR effects on auditory processing were specific to estrogen depletion, a third imaging session was performed in May/ June 10 min after an acute injection of E2 along with VOR.

\section{Materials and Methods}

Animals. Experiments were performed on nine wild-caught male European starlings (Sturnus vulgaris, $\pm 75-95 \mathrm{~g}$ ). Birds were caught as adults in Normandy (France) in November 2006. They were first kept together in an indoor aviary with an artificial light/dark cycle simulating the natural photoperiod and later in outdoor aviaries at the University of Rennes 1 (Rennes, France) with food and water ad libitum. At the University of Antwerp (Belgium), they were housed in one indoor aviary $(1.40 \times$ $2.20 \times 2.10 \mathrm{~m}$ ) under an artificial light/dark cycle simulating the natural photoperiod until 6 months before the start of the experiment, when they were placed in short day length $(8 \mathrm{~h}$ light $/ 16 \mathrm{~h}$ dark). Throughout the experiment, all males were kept together in a single aviary with six other wild-caught females. Food and water were available ad libitum. All birds were individually marked with color bands. Experimental procedures were in agreement with the Belgian laws on the protection and welfare of animals and were approved by the ethical committee of the University of Antwerp (License number: 2013-18).

Experimental design and endocrine manipulations. All males were imaged twice by fMRI in December 2013 ( 8 h light/16 h dark), March 2014 (11 h light/13 h dark) and May/June 2014 (16 h light/8 h dark). Birds were maintained in a short day photoperiod ( $8 \mathrm{~h}$ light $/ 16 \mathrm{~h}$ dark) for 6 months before the beginning of the experiment to make them photosensitive. They were then implanted in the dorsal neck region with a $12-\mathrm{mm}$ long capsule made of SILASTIC tubing (Dow Corning; inner diameter, $1.47 \mathrm{~mm}$; outer diameter, $1.96 \mathrm{~mm}$ ), filled with crystalline T and sealed on both ends with SILASTIC glue. Three weeks later, in December 2013, all birds were imaged using fMRI while still in the $8 \mathrm{~h}$ light/16 h dark cycle. Birds were then switched to a light regime mimicking the natural photoperiod (duration of the $\mathrm{L} / \mathrm{D}$ cycles was adjusted each week) and again imaged by fMRI in early March 2014 (while in $11 \mathrm{~h}$ light/13 h dark) and at the end of May 2014/beginning of June 2014 (while in the $16 \mathrm{~h}$ light $/ 8 \mathrm{~h}$ dark cycle). The birds were implanted with new SILASTIC T implants 3 weeks before each fMRI session and old, now empty, implants were removed at that time. On each recording session, each individual was imaged twice consecutively by fMRI in two endocrine conditions (Fig. 1A): a control session (35 min) directly followed by a another session ( $35 \mathrm{~min}$ ) that was started $10 \mathrm{~min}$ after an intraperitoneal injection of the aromatase inhibitor vorozole (6-[(4-chlorophenyl) $(1 H$-1,2,4-triazol-1-yl)methyl]-1-methyl-1 $H$-benzotriazole; $30 \mathrm{mg} / \mathrm{kg}$; Figure $1 A)$. In May/June, a third imaging session was performed in sequence starting 10 min after an injection of estradiol (E2) performed at the end of the VOR imaging session $(0.5 \mathrm{mg} / \mathrm{kg}$ i.p, condition VOR+E2; Fig. $1 B)$. Three sets of stimuli were used in each imaging session: songs carrying speciesspecific or individual information and pure tones (Fig. 1C).

Previous work demonstrates that a systemic injection of VOR acutely inhibits aromatase activity in the avian brain with the time frame used in the present study. For example, a recently published paper (Alward et al., 2016) clearly shows that aromatase activity in the NCM of another seasonal songbird (the canary) is significantly reduced by another aromatase inhibitor, fadrozole that is similar to vorozole, at $30 \mathrm{~min}$ after a systemic injection. Four hours after injection aromatase activity was back to baseline level (same as control group). The dose of vorozole used here had also been shown to completely inhibit within $30 \mathrm{~min}$ brain aromatase activity in quail (Cornil et al., 2006b).

Beak color. The beak color of all subjects was assessed just before each session of fMRI imaging. Beak color in European starlings is dependent on plasma T (Dawson and Howe, 1983; Ball and Wingfield, 1987). It changes from yellow (when plasma T levels are high) to black (when plasma $\mathrm{T}$ levels are basal). It was recorded on an arbitrary scale ranging from 0 (bill entirely black, from base to tip) to 5 (bill entirely yellow) (De Ridder et al., 2002). During all fMRI measurements, the beak of all males $(N=9)$ was yellow $(4.0 \pm 0.51$; range, $3.5-4.8)$. This confirmed that high concentrations of $\mathrm{T}$ were present in the blood of all birds due to the T-implants that were implanted 3 weeks before each fMRI session.

fMRI. Imaging was performed in anesthetized subjects on a horizontal MR system (Pharmascan 70/16 US, Bruker Biospin) with a magnetic field strength of 7 tesla as previously described (De Groof et al., 2013). BOLD fMRI data were acquired using a $\mathrm{T}_{2}$-weighted fast-spin echo sequence [echo time/repetition time: 60/2000 ms] (De Groof et al., 2013). Each whole-brain volume contained 15 sagittal slices, $1 \mathrm{~mm}$ thick, with a gap of $0.066 \mathrm{~mm}$ between slices. In-plane resolution was $0.34 \times 0.34 \mathrm{~mm}^{2}$ and matrix size was $64 \times 64$ voxels. Anatomical three-dimensional (3D) images required for localization of the functional data (see below) were obtained for each bird using a RARE $\mathrm{T}_{2}$-weighted sequence with TE/TR: $60 / 2000 \mathrm{~ms}$. Voxel size was $0.085 \times 0.085 \times 0.085 \mathrm{~mm}^{3}$ and matrix size was $256 \times 256 \times 256$ voxels.

Each session included three sound stimuli: PTs, SPEC warbling, and INDIV warbling motifs (Fig. 1C). Each session consisted of an ON/OFF 
A

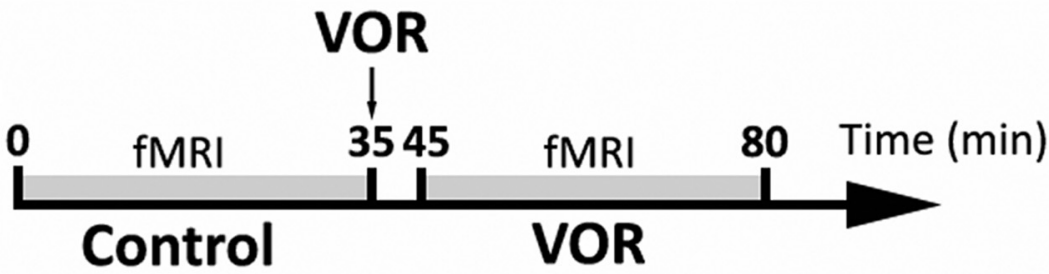

B

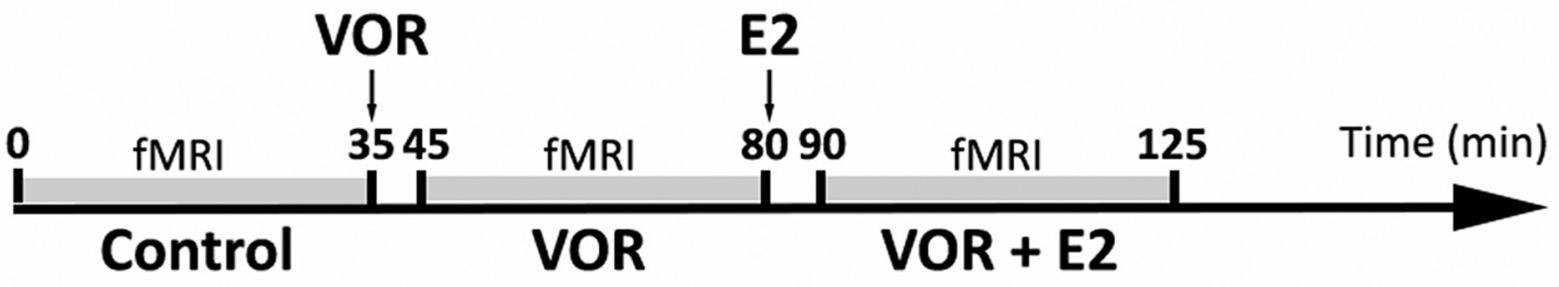

C
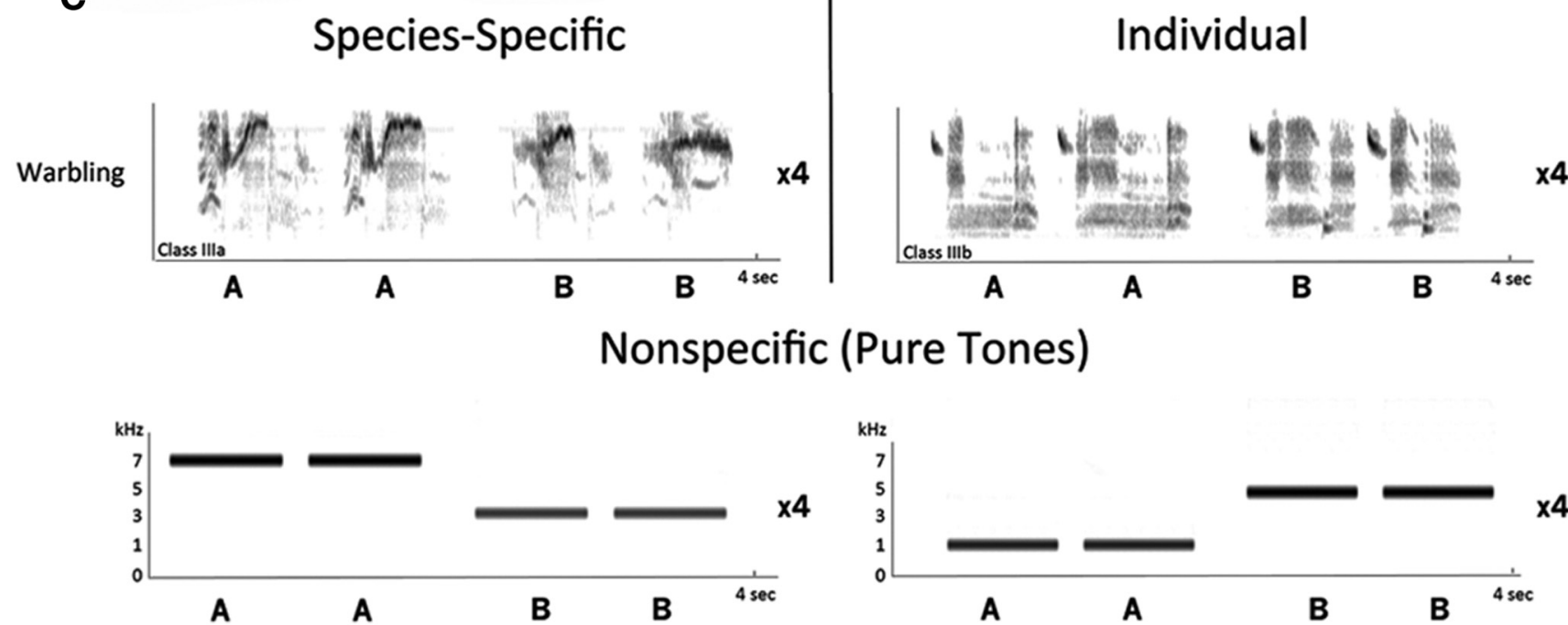

Figure 1. A, Experimental design used in December and March to test the effect of acute aromatase blockade (VOR; $30 \mathrm{mg} / \mathrm{kg})$. Arrow indicates when VOR was injected. Each fMRI session lasted for $35 \mathrm{~min}$ and VOR injection was done $10 \mathrm{~min}$ before fMRI. B, Experimental design used in May/June to test the effect of acute aromatase blockade (VOR; $30 \mathrm{mg} / \mathrm{kg})$ and acute E2 (0.5 mg/kg) when aromatase is acutely inhibited (VOR + E2). Arrows indicate when VOR or E2 were injected. Each fMRI session lasted for 35 min and injections were done 10 min before. $\boldsymbol{C}$, Sonograms of the stimuli used. Stimuli bearing species-specific and group information consisted of two species-specific warbling motifs; stimuli bearing individual information consisted of two individual warbling motifs. Nonspecific stimuli consisted of pure tones $(1,3,5$, and $7 \mathrm{kHz})$. The depicted sequence of songs or sounds (AABB) was repeated four times per stimulus, bringing the total length of each stimulus to $16 \mathrm{~s}$.

block design alternating auditory stimulation periods (ON blocks) with resting periods (OFF blocks). Each block (ON and OFF) lasted $16 \mathrm{~s}$, which corresponds to the acquisition time of two images (each image of the whole brain takes $8 \mathrm{~s}$ to acquire). Each stimulus type was presented 42 times, resulting in the acquisition of 84 images per stimulus and per subject. The presentation order of the stimuli was counterbalanced within and between subjects. Each individual starling was presented with the same set of three stimuli each time it was measured with fMRI (each acute treatment in each season).

\section{Stimuli and stimulation device}

Both artificial nonspecific sounds and natural starling vocalizations corresponding to the distinct types of starling songs (Hausberger et al., 1997) were used. In total, three types of stimuli were used as follows (Fig. 1C):

- Artificial pure tone stimuli (one stimulus made out of PTs at 7 and $3 \mathrm{kHz}$ and another one made out of PTs at 1 and $5 \mathrm{kHz}$, both stimuli interleaved with silence periods of $0.5 \mathrm{~s}$ ).

- Two types of starling song stimuli consisting of songs bearing either species-specific and group information (songs shared by all males) or individual information, each recorded from two different starlings unknown to the birds (hence all song stimuli can be consid- ered to be novel or unfamiliar; see De Groof et al., 2013 for the full description of these different elements of the starling song and details regarding their selection as stimuli for this and previous experiments):

- Species-specific warbling (high-pitched trills taken from the terminal, non-individual part of warbling that is found in the repertoire of all male starlings).

- Individual warbling (individual motifs taken from the initial, individual part of warbling).

The total duration of each stimulus was $16 \mathrm{~s}$ and consisted of two elements $(A$ and $B)$ of the same type of song repeated in a $[(A A B B) \times 4]$ fashion (Fig. 1C). The intensity of each song was normalized (in terms of matched root-mean-square to $67 \mathrm{~dB}$, in comparison magnet noise was $65 \mathrm{~dB}$ ) before being integrated into the complete stimulus (songs and silence periods). These manipulations were done using Praat software (University of Amsterdam, The Netherlands).

During imaging experiments, auditory signals were presented to the birds with nonmagnetic dynamic speakers connected to an amplifier as described previously (Van Meir et al., 2005). Stimulus presentation was controlled by Presentation software 0.76 (Neurobehavioral Systems; 
RRID:SCR_002521). Frequencies between 2500 and $5000 \mathrm{~Hz}$ are known to be enhanced in the setup (Poirier et al., 2009). To compensate for this artificial enhancement, an equalizer function was applied to each stimulus using WaveLab software (Steinberg; De Groof et al., 2013).

\section{Anesthesia and physiology monitoring}

During the experiment, birds were anesthetized with an intramuscular injection in the chest of $0.4 \mathrm{ml}$ of a mixture containing $10 \mathrm{ml}$ of medetomidine (1 mg/ml, Domitor, Orion) and $0.5 \mathrm{ml}$ of ketamine $(50 \mathrm{mg} / \mathrm{ml}$, Ketalar, Parke-Davis). Body temperature was continuously monitored with a cloacal temperature probe and maintained at $41.5 \pm 0.5^{\circ} \mathrm{C}$ by a feedback controlled warm air heating system (SA-Instruments). Respiration rate and amplitude were constantly monitored with a small pneumatic sensor (SA-Instruments; RRID:SCR_002090) positioned under the bird. To maintain anesthesia at a constant depth based on these measures of respiration, the anesthetic mixture was continuously infused at a rate of $0.10 \mathrm{ml} / \mathrm{h}$ through a catheter positioned in the chest muscle.

\section{Image processing}

Intra-individual head motion (from the different sessions) was corrected with a six-parameter rigid body spatial transformation using the Statistical Parametric Mapping toolbox (SPM12; Wellcome Trust Department of Cognitive Neurology, London, UK; ; RRID:SCR_007037). The realigned fMRI images for each subject were then coregistered to each individual anatomical 3D dataset. In parallel, the 3D dataset was spatially normalized using SPM12 with a high-resolution ex vivo starling MRI atlas (De Groof et al., 2016). The transformation matrix of this spatial normalization was then applied to the realigned and coregistered functional data, resulting in functional data precisely coregistered to the atlas dataset. Finally, functional data were smoothed with a $0.68 \mathrm{~mm}$ width Gaussian kernel.

Aromatase activity. After the last imaging session in May/June 2015, birds were kept in natural photoperiod for another 6 months. In January 2015 ( $8 \mathrm{~h}$ light $/ 16 \mathrm{~h}$ dark), subjects $[n=8$, one individual died between the last fMRI measurement (June) and January of the next year] were killed by rapid decapitation 3 weeks after a new $\mathrm{T}$ treatment. The brains were then dissected out of the skull, flash frozen on dry ice and kept at $-80^{\circ} \mathrm{C}$ before further use.

Microdissections. Brain regions of interest were microdissected in a cryostat. Briefly, the brain was cut in $200-\mu \mathrm{m}$-thick coronal slices with the plane of section adjusted to the canary stereotaxic atlas (Stokes et al., 1974). Individual regions were then collected by cutting them out with a scalpel. The left and right sides of three regions [hypothalamic/preoptic area (HPOA), NCM, and caudomedial nidopallium (CMM)] were dissected and stored separately resulting in 6 different samples per brain. The HPOA was collected from the most rostral section $(200 \mu \mathrm{m})$ containing the full extension of the tractus septopallio-mesencephalicus (TSM) to the most caudal section containing the end of the anterior commissure (CA). For each section, the dissection was defined by a dorsal cut performed ventral to the septum, a lateral cut at the most lateral edge of the diencephalon (defined as the junction between each telencephalon and optic lobe) and a medial cut at the level of the third ventricle to separate the left and right sides. In the most posterior sections an additional oblique cut was performed at the basis of the diencephalon to remove each optic lobe. A rostral mediodorsal telencephalic region containing the CMM and a caudal mediodorsal telencephalic region containing the NCM were then collected. Sections comprised between the full extension of TSM and the end of the telencephalon were collected and divided into a rostral part and a caudal part containing an equal number of sections each. Both regions were delimited by a dorsoventral cut parallel to the interhemispheric line aligned to the point where the telencephalon meets the optic lobe, a medial cut between each hemisphere to separate the left and right sides and a ventral cut at the level of the lamina medullaris dorsalis for the rostral sections and at the level of the lamina archistriatalis dorsalis for the most caudal sections. In addition to the target regions (CMM and NCM, respectively) these microdissections also contained parts of the hippocampus and septum. Microdissected tissues were immediately transferred into refrigerated 1.5 $\mathrm{ml}$ tubes kept on dry ice and stored at $-80^{\circ} \mathrm{C}$ until further use.
Aromatase activity assay. Microdissected tissue samples were homogenized in ice-cold TEK buffer (10 mM Tris-HCl, $1 \mathrm{~mm}$ Na-EDTA, $150 \mathrm{~mm}$ $\mathrm{KCl}, \mathrm{pH} 7.2 ; 5 \mathrm{mg}$ fresh weight in $50 \mu \mathrm{l}$ of buffer) with a glass pestle fitting the $1.5 \mathrm{ml}$ tubes and stored at $-80^{\circ} \mathrm{C}$ until assayed. Aromatase activity (AA) was quantified by measuring the production of tritiated water associated with the conversion of $\left[1 \beta-{ }^{3} \mathrm{H}\right]$-androstenedione into estrone as described previously (Cornil et al., 2011). Sample duplicates were incubated in the presence of TEK buffer, ${ }^{3} \mathrm{H}$-androstenedione (final concentration $25 \mathrm{nM}$, specific activity $24 \mathrm{Ci} / \mathrm{mmol}$; PerkinElmer), and $\mathrm{NADPH}(4.8 \mathrm{~mm})$ at $37^{\circ} \mathrm{C}$ for $15 \mathrm{~min}$. An extra tube was assayed for each sample containing homogenate in the presence of an excess of the potent and specific aromatase inhibitor, VOR ( $40 \mu \mathrm{M}$ final concentration) to discriminate between specific and nonspecific enzymatic activity. The reaction was stopped by adding $2 \%$ activated charcoal in $10 \%$ trichloroacetic acid. Samples were then centrifuged to collect the supernatant $\left(\mathrm{H}_{2} \mathrm{O}\right.$ and $\left.{ }^{3} \mathrm{H}_{2} \mathrm{O}\right)$ that was filtered through Dowex cation exchange columns. ${ }^{3} \mathrm{H}$-water was quantified by adding Optiphase HiSafe 3 (PerkinElmer) and counting for $3 \mathrm{~min}$ on a Wallac Winspectral 1414 Liquid Scintillation Counter. All samples were run in one single assay and enzymatic activity was expressed in femtomoles per hour after correction for quenching, recovery, and blank values.

Statistical analysis. Statistical voxel-based analyses of the fMRI were performed as described previously (De Groof et al., 2013), with some modifications. Statistical voxel-based analyses were performed using a massunivariate approach based on the general linear model implemented in SPM12. High-pass temporal filtering with a cutoff of $352 \mathrm{~s}$ was performed to remove low-frequency drifts. The cutoff value was selected to be twice the maximum interval (in seconds) between two stimuli of the same kind (here $2 \times 11$ periods of $16 s=352 \mathrm{~s}$ ). . odel parameters were then estimated using a classical restricted maximum likelihood algorithm.

On the individual-level, a general linear model convolved with the canonical hemodynamic response function was applied. Separate regressors were included that modeled the onsets of the auditory stimuli "INDIV", "SPEC", and "PT" for each endocrine session (Control, VOR, and VOR + E2). The six estimated head movement parameters were included in the design matrix to account for the residual effects of head motion.

On the second level, a group analysis was performed on the effects identified by the previous analysis. A whole-brain random-effect flexible factorial model $(3 \times 2 \times 3$ repeated-measures ANOVA) was designed including as within factors the seasons (December, March, May/June), acute treatments (control, VOR), and stimuli (INDIV, SPEC, PT). Main effects of the three factors and their three-way (i.e., seasons $\times$ acute treatments $\times$ stimuli) and two-way interactions (i.e., seasons $X$ acute treatments, seasons $X$ stimuli, acute treatments $X$ stimuli) were explored, only looking at voxels that showed a significant BOLD response to any of the stimuli during any of the time points (acute treatments and photoperiods) indicated by the onesample $t$ tests $\left(p_{\mathrm{FWE}}<0.05\right)$.

In May/June we also looked at the effect of estrogens on auditory selectivity (INDIV songs vs SPEC songs). We did this using a $3 \times 3$ repeated-measures ANOVA (first within factor: control, VOR and VOR + E2 conditions; second within factor: 3 stimuli). We tested for a differential effect between SPEC and INDIV song stimuli (INDIV > SPEC) during the control condition and focused exclusively on these voxels in post hoc $t$ tests comparing acute treatments.

Because statistical tests were performed on a voxel basis, many tests were made; $p$ values were adjusted to the number of independent tests performed. This was done using the familywise error (FWE) method. This method uses the random field theory to calculate the number of independent tests. It takes into account the number of voxels but also the amount of auto-correlation among the data. To compare responses obtained in both hemispheres, we calculated for each subject the differential effect between Control and VOR conditions for all photoperiods. This was done in the two left NCM clusters (rostral and caudal) found to show either a significant main effect of treatment or a photoperiod $\times$ treatment interaction (see Results) and in their mirror counterpart in the right hemisphere. These differential effects were then compared across hemispheres using two-tailed paired $t$ tests. 
INDIV > PT
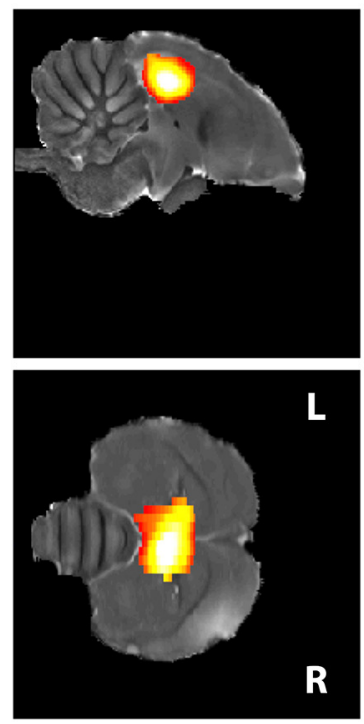
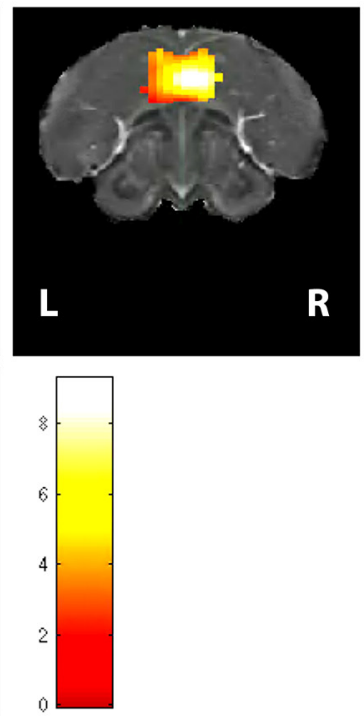

SPEC > PT
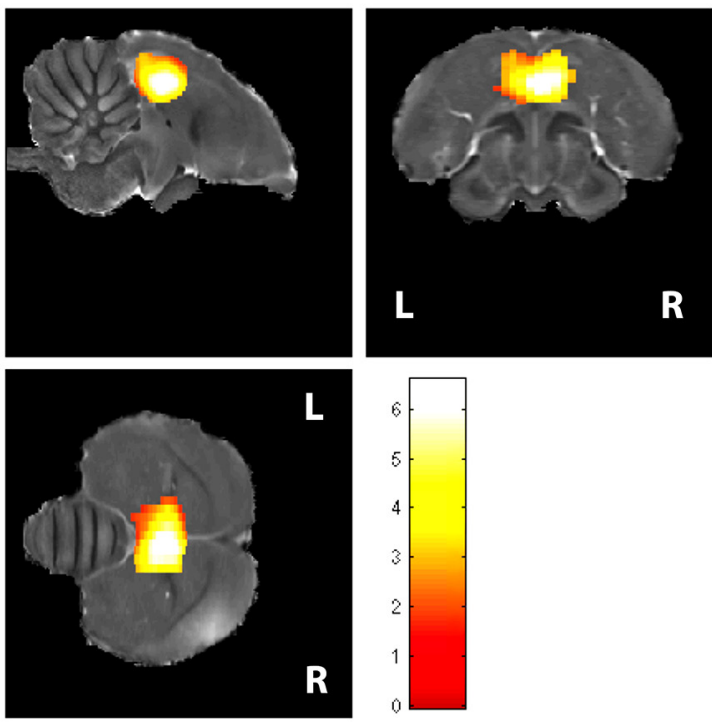

Figure 2. Regions showing a main effect of stimulus. INDIV $>$ PT: regions showing enhanced responses during individual songs versus pure tones; SPEC $>$ PT: regions showing enhanced responses during species-specific songs versus pure tones. The threshold was set at $p<0.05$.

Relationships between individual differences in BOLD values (average BOLD value of all voxels in the NCM clusters defined above; i.e., the rostral and caudal NCM clusters associated with a significant main effect of the treatment or with a photoperiod by treatment interaction, as well as their mirror counterpart in the right hemisphere) were analyzed with the Pearson product moment correlation coefficient $(r)$. We assessed the existence of correlations across seasons between the baseline BOLD values and between the magnitude of the treatment effect (control-VOR) within each hemisphere. Correlations were considered significant for an $\alpha$ level of $p<0.05$. Aromatase activities were compared by paired Student's $t$ test. Differences were considered statistically significant for $p<0.05$. Unless otherwise mentioned, all data are presented as mean \pm SEM.

\section{Results}

Rapid effect on BOLD response in NCM of estrogen depletion during different seasons

We first ran a whole-brain three-way repeated-measures ANOVA with treatments (control vs VOR), stimuli (INDIV songs, SPEC songs, PT) and seasons (December, March, May/June) as factors to identify brain regions where the BOLD response was affected by these factors. We found strong main effects of stimulus in a cluster containing bilateral NCM/Field L/CMM and of treatment in a cluster in left rostral NCM/Field L. There was also a trend for a season $X$ treatment interaction in a cluster in left caudal NCM (cluster level familywise error corrected $p=0.055$ ). All regions mentioned here were significant at $p<0.05$ for cluster-level familywise error corrected with the uncorrected voxelwise $p<0.001$. No significant cluster was detected under the same threshold in any other contrast for either the main effect of seasons or the other interactions (season $\times$ treatment $\times$ stimuli, season $\times$ stimulus or stimulus $\times$ treatment).

Further analysis of the main effect of stimulus showed that the bilateral NCM/Field L/CMM complex had stronger activity during INDIV relative to PT and during SPEC relative to PT (Fig. 2). Reverse and other (INDIV $>$ SPEC or SPEC $>$ INDIV) contrasts yielded no results.

Further analysis of the main effect of treatment showed a stronger activity in left rostral NCM/Field L during the control than VOR condition (Fig. 3, left). The reverse contrasts yielded no results. The rapid effect of VOR was most pronounced during March compared with December or May/ June. Although there was no main effect of seasons, there was a significant overall decrease in responses to song during the control condition in May/June compared with March (and a trend compared with December $\left(P_{\text {uncorrected }}=0.006 ; P_{\mathrm{FWE}}=\right.$ 0.287 ) in this region.

The season $\times$ treatment interaction in the left caudal NCM, was attributable to a significant treatment effect (control $>$ VOR) in March, but not in December or in May/June (Fig. 3, right). Although there was no main effect of seasons, there was also a significant decrease in responses to song during the control condition in May/June compared with March and December in this region.

We then wondered whether the effect of stimuli would be differentially affected by the treatment $\times$ season interaction. Therefore, we analyzed the data comparing the effect of treatment and stimuli for each season separately (Fig. 4). In December, VOR caused a rapid (within 10-45 min) significant change in auditory-evoked BOLD responses in left rostral NCM/Field L. Post hoc analysis revealed that BOLD was reduced during VOR treatment (relative to the control condition) for INDIV songs stimuli $\left(P_{\mathrm{FWE}}=0.055\right)$. BOLD during playback of SPEC songs $\left(P_{\mathrm{FWE}}=0.235\right)$ and PT $\left(P_{\mathrm{FWE}}=0.198\right)$ stimuli were not significantly reduced but showed similar overall decreases in response to VOR.

In March, VOR also caused a rapid (within 10-45 min) significant decrease in auditory-evoked BOLD responses in left $\mathrm{NCM} /$ Field L, however the decrease was much more pronounced and was also including the more caudal parts of NCM. Post hoc analysis revealed that BOLD was reduced during VOR treatment (relative to the control condition) for all stimuli (INDIV: $P_{\mathrm{FWE}}=$ 0.025; SPEC: $P_{\mathrm{FWE}}=0.011$; PT: $\left.P_{\mathrm{FWE}}=0.090\right)$.

In May estrogen depletion caused a rapid (within $45 \mathrm{~min}$ ) significant change in auditory-evoked BOLD responses again in left rostral NCM/Field L only and post hoc analysis revealed that 
Main effect Treatment (Control > VOR)
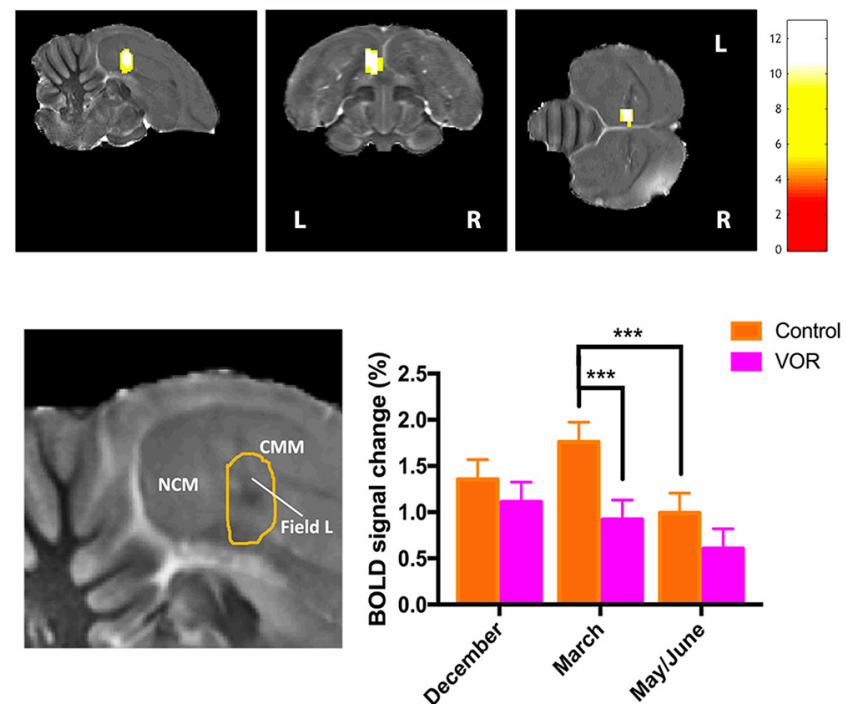

\section{Season $\mathrm{x}$ treatment interaction}
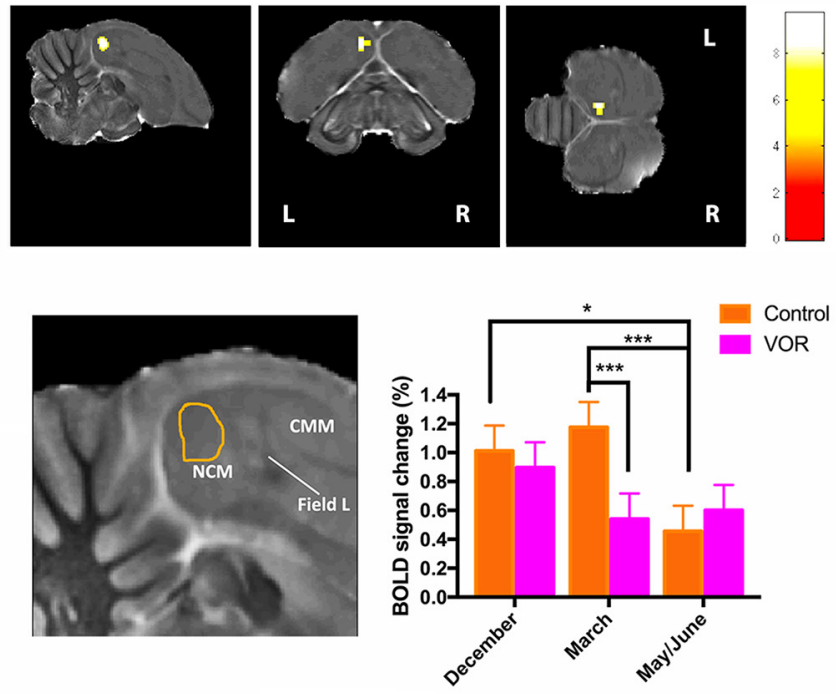

Figure 3. Left, Statistical map of regions displaying a significant main effect of treatment (control $>$ VOR). Only left rostral NCM/Field L (enlarged in the high magnification adjacent to the bar graphs) is showing reduced responses in VOR versus control conditions ( $t$ test). $t$ Values are color-coded according to the scale displayed. The threshold was set at $p_{\text {uncorrected }}<0.01$. Bar graphs: plots of relative response amplitude ( + SEM) of the local peak voxel in the left rostral NCM/Field L cluster. Zero level corresponds to mean activation during rest periods. Right, Statistical map of regions displaying a significant season $\times$ treatment interaction ( $F$ test). $F$ values are color-coded according to the scale displayed. The threshold was set at $p_{\text {uncorrected }}<0.01$. Only the left caudal NCM (enlarged in the high magnification adjacent to the bar graphs) shows a differential response in control versus VOR between seasons. Bar graph: average of the relative response amplitude ( $+S E M$ ) of neural activations elicited by all stimuli (INDIV, SPEC, and PT) per session in the cluster illustrated at the top (values from the voxel with the maximum F value). Zero level corresponds to mean activation during rest periods. ${ }^{* * *} p_{\mathrm{FWE}}<0.05 ;{ }^{*} p_{\text {uncorrected }}<0.01$.

DECEMBER
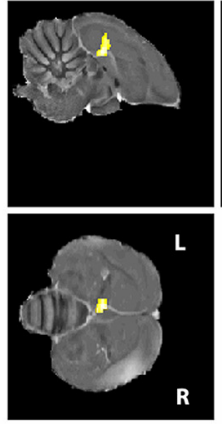

$\mathbf{L}$
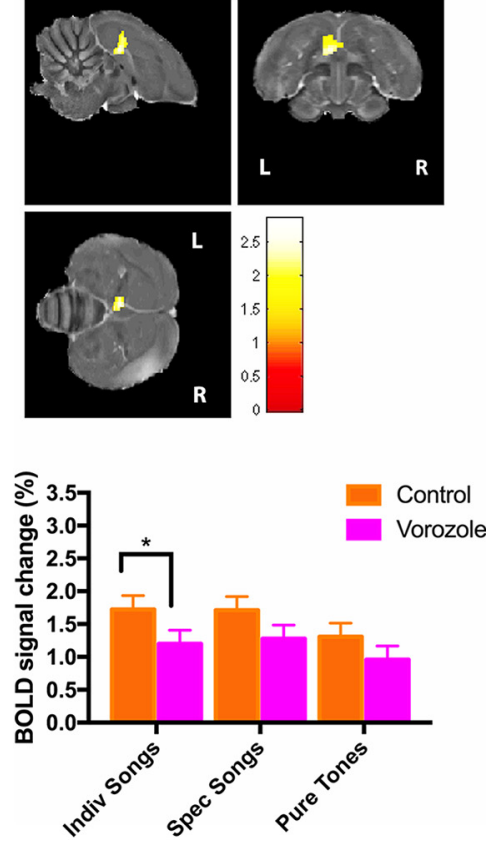

MARCH
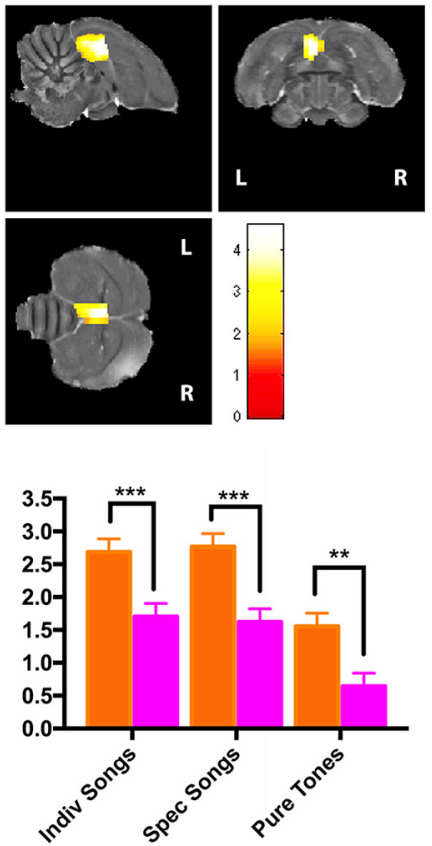

MAY/JUNE
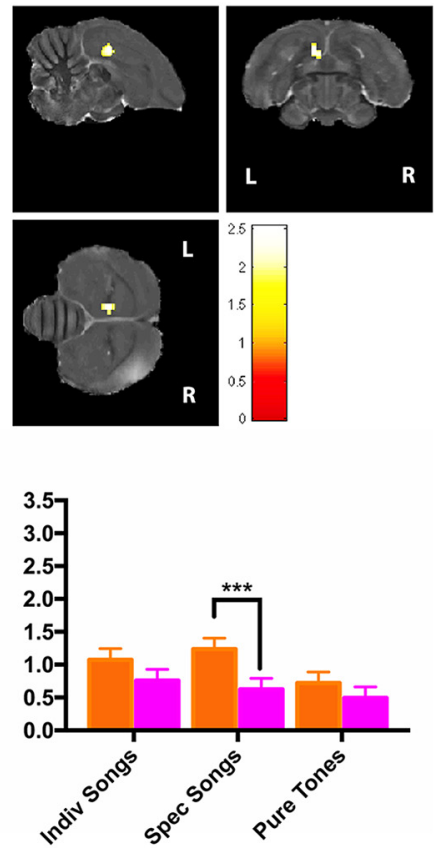

Figure 4. Statistical map of regions displaying a significant main effect of treatment for each season separately. Left rostral NCM/Field $L$ is showing reduced responses in VOR versus control conditions ( $t$ test) in all seasons, but in March also the caudal part of NCM shows reduced responses with VOR. $t$ Values are color-coded according to the scale displayed. The threshold was set at $p_{\text {uncorrected }}<0.05$. Bar graphs: plots of relative response amplitude ( + SEM) of the local peak voxel per season. Zero level corresponds to mean activation during rest periods. Stars indicate significant differences between control and VOR conditions $\left({ }^{* * *} p_{\text {FWE }}<0.05 ;{ }^{* *} p_{\text {uncorrected }}<0.001 ; p_{\text {uncorrected }}<0.01\right)$.

BOLD was significantly reduced during VOR treatment (relative to the control condition) only for SPEC $\left(P_{F W E}=0.012\right)$. BOLD during playback of INDIV $\left(P_{\mathrm{FWE}}=0.833\right)$ and $\mathrm{PT}\left(P_{\mathrm{FWE}}=\right.$ 0.832 ) stimuli was not significantly reduced in response to VOR.
Lateralized effect of acute estrogen depletion on auditory activation

In the previous analyses, the differential BOLD response between control and VOR conditions was observed in left but not in right 
A

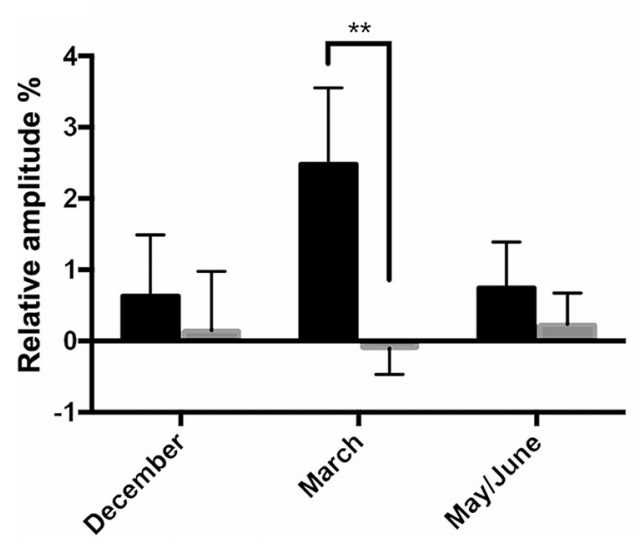

B

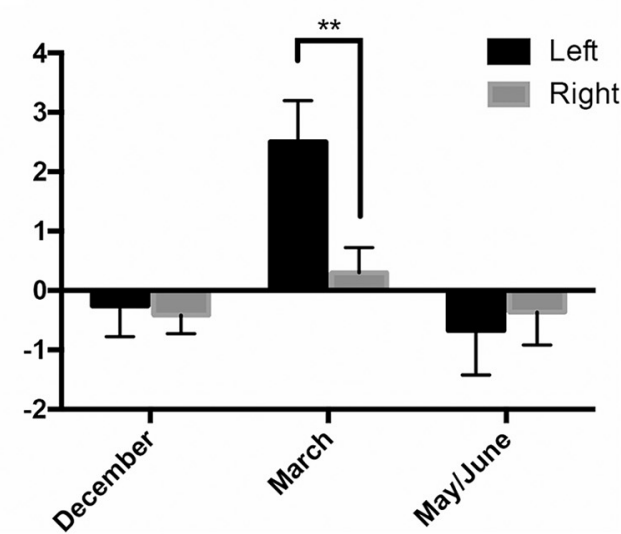

Figure 5. Lateralization of VOR effects. Relative amplitudes (percentage) of differential (control - VOR) responses to all auditory stimuli (INDIV, SPEC, and PT) pooled in left (black bars) and right (gray bars) rostral $(\boldsymbol{A})$ and caudal ( $\boldsymbol{B})$ NCM. Positive values indicate that the region of interest was more activated during control than during VOR treatment and vice versa. The error bars correspond to SEMs across subjects. Stars indicate that the difference between left and right NCM clusters is significant by post hoc tests $\left({ }^{* *} p<0.01\right)$.

NCM/Field L. To test whether there is a true lateralization of these responses, we directly compared the left and right clusters defined as the functional regions identified on the left side by the previous main effect of treatment (for rostral NCM/Field L; Fig. 3 , left) and by the season $\times$ treatment interaction (for caudal NCM; Fig. 3, right) and their respective mirror counterparts on the right side. We ran two separate two-way repeated ANOVAs (within-subject factors: hemispheres and seasons) on data for the pooled three stimuli using the differential BOLD response observed (Control - VOR). Analyses for the rostral NCM/Field L (where a main treatment effect had been observed) revealed a significant interaction between hemisphere and season $\left(F_{(2,12)}=\right.$ 4.466, $p=0.0355$ ), driven by a left lateralized effect of VOR on BOLD responses in March $\left(t_{(12)}=2.276, p=0.0021\right)$ but not in December $\left(t_{(12)}=0.405, p=0.7973\right)$ nor in May/June $\left(t_{(12)}=\right.$ $0.654, p=0.771$; Fig. $5 A$ ). A trend for a main effect of hemisphere was observed $\left(F_{(1,6)}=5.578, p=0.0562\right)$, whereas there was no main effect of season $\left(F_{(2,12)}=0.4181, p=0.6675\right)$.

A similar two-way ANOVA for caudal NCM (where a trend for a season $X$ treatment interaction had been observed) also revealed a significant interaction between hemisphere and season $\left(F_{(2,12)}=6.322, p=0.0133\right)$, driven again by a left lateralized effect of VOR on BOLD responses in March $\left(t_{(12)}=2.692, p=\right.$ $0.0040)$ but not in December $\left(t_{(12)}=0.265, p=0.9873\right)$ nor in May/June $\left(t_{(12)}=0.332, p=0.9213\right.$; Fig. $\left.5 B\right)$. The analysis also revealed a main effect of season $\left(F_{(2,12)}=5.097, p=0.025\right)$ however there was no main effect of hemisphere $\left(F_{(1,6)}=2.891, p=\right.$ $0.140)$. In summary, the rapid modulation of auditory-evoked BOLD activity by acute aromatase inhibition was lateralized to the left hemisphere specifically in March, especially in caudal NCM where there was in addition a season effect.

\section{Correlation analyses}

No significant correlation was detected across seasons between the average BOLD value in the rostral or caudal NCM (left or right). The intra-individual BOLD value changes (control VOR) in the right rostral NCM in December and March were negatively correlated $(r=-0.795, p=0.032)$, i.e., birds presenting a large BOLD change in December presented a small BOLD change in March and vice versa. No other correlations between seasons were detected. Individual values observed during different seasons were thus largely independent and it cannot be ex- cluded that the single (negative) correlation observed only reflected a type 2 error [one correlation out of $12(2$ ROI $\times 3$ seasons $\times 2$ dependent measures] is significant and is unexpectedly negative).

\section{Effects of exogenous estrogens following aromatase inhibition}

To test whether exogenous estrogens (E2) can reverse VOR effect, an additional acute treatment (VOR+E2) was tested in May/ June. We compared the differential BOLD responses between the three endocrine conditions using a repeated measure wholebrain two-way ANOVA with treatments (control, VOR, and VOR + E2) and stimuli (INDIV, SPEC, and PT) as factors. This revealed a strong main effect of stimulus (in bilateral NCM/Field $\mathrm{L} / \mathrm{CMM}$ regions) and a strong treatment $\times$ stimulus interaction (in bilateral rostral NCM/Field L; Fig. 6). All regions mentioned here were significant at $p<0.05$ cluster-level familywise error corrected with the uncorrected voxelwise $p<0.001$. No significant cluster in the contrast for the main effect of treatment was detected under the same threshold.

Further analysis of the main effect of stimulus showed that the bilateral NCM/Field L/CMM complex was activated significantly more strongly by INDIV compared with PT and by INDIV compared with SPEC. Reverse and other $($ SPEC $>$ PT) contrasts yielded no results (data not shown).

To further disentangle the treatment $\times$ stimulus interaction in the left and right rostral NCM/Field L complex separately (Fig. 6), we ran for each cluster (left and right) three separate one-way ANOVAs (one for each stimulus type) with treatments as repeated factor. BOLD response with INDIV song stimuli was rapidly and significantly increased by E2 $(\mathrm{VOR}+\mathrm{E} 2>$ control and VOR $+\mathrm{E} 2>$ VOR) both in left and right NCM. BOLD response during SPEC songs was rapidly and significantly reduced by VOR (control $>$ VOR) in the left but not the right rostral NCM/ Field L and this was not reversed by E2 (VOR +E2; Fig. 6). No effect of treatment was detected for PT in either left or right rostral NCM/Field L.

Auditory processing in NCM was previously shown to change with seasons. Specifically selectivity for songs used in individual recognition compared with species-specific songs (INDIV vs SPEC selectivity) is higher during the breeding season in caudal NCM (De Groof et al., 2013). It was suggested that estrogens could play a potential role in this seasonal change. We therefore 


\section{Treatment x stimulus interaction}
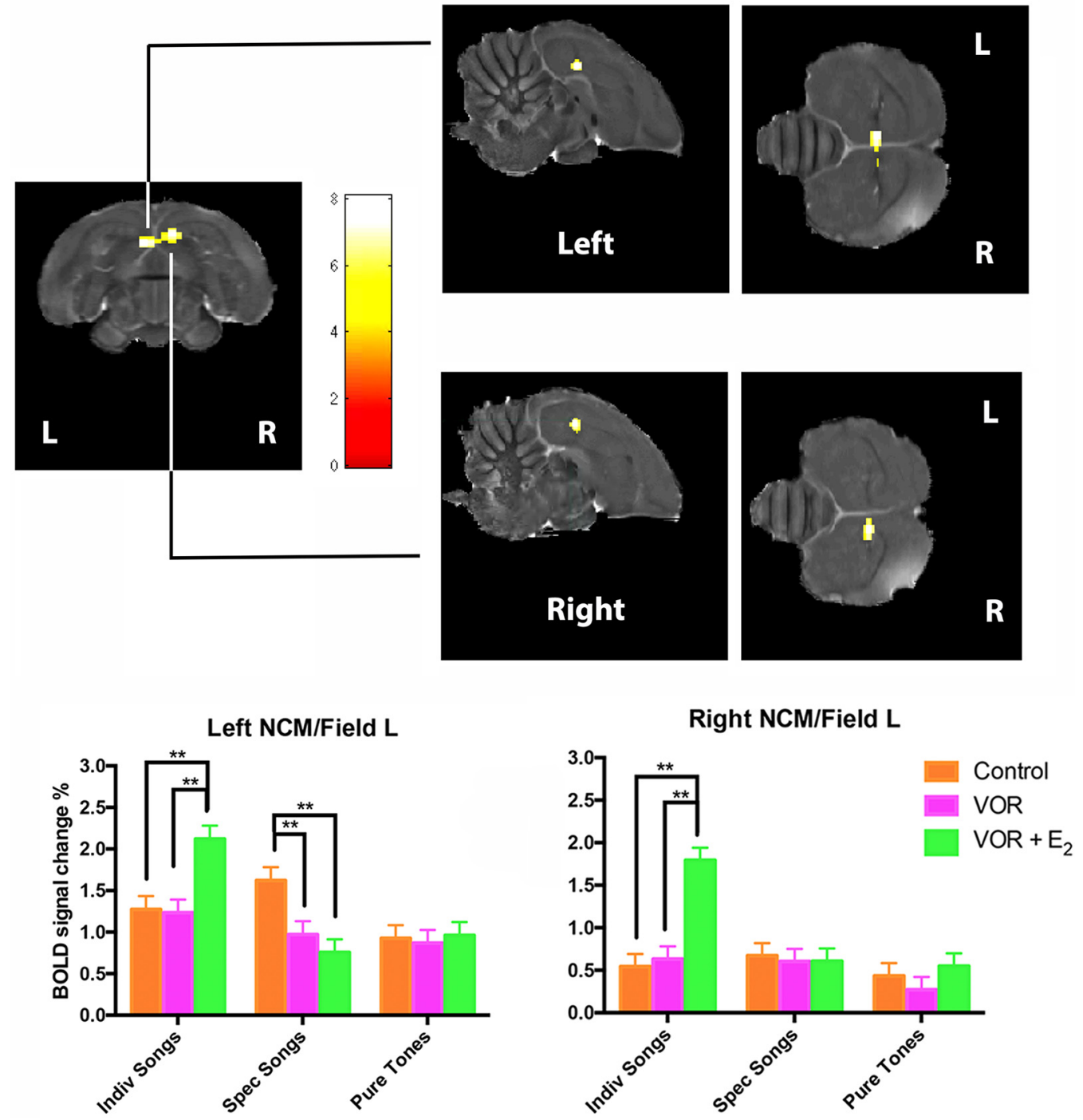

Figure 6. Statistical map of regions displaying a significant treatment $\times$ stimulus interaction ( $F$ test). Fvalues are color-coded according to the scale displayed. The threshold was set at $p_{\text {uncorrected }}<0.001$. Bar graphs: plots of relative response amplitude ( $\left.+S E M\right)$ of the local peak voxel in the left and right rostral NCM/Field L cluster. Zero level corresponds to mean activation during rest periods. Stars indicate significant differences between treatments $\left({ }^{* *} p<0.001\right)$.

looked at the effect of estrogen manipulation on this selectivity in auditory processing. INDIV versus SPEC selectivity was observed in the control session in the left caudal NCM $(t$ test: INDIV $>$ SPEC songs: $\left.T_{\max }=1.85, P_{\text {uncorrected }}=0.034, P_{F W E}=0.109\right)$. Aromatase inhibition abolished this selectivity in this region $\left(T_{\max }=0.21, P_{\text {uncorrected }}=0.340\right)$ and estradiol reversed this effect $\left(T_{\max }=2.54, P_{\text {uncorrected }}=0.007, P_{\mathrm{FWE}}=0.027 ;\right.$ Fig. 7$)$.

\section{Aromatase activity}

Because aromatase inhibition was producing differential effects on the auditory activity in the left and right hemispheres, we wondered whether this lateralization could relate to a differential AA in the two hemispheres. The enzymatic activities measured in the HPOA and in two telencephalic regions, including CMM and NCM respectively, confirmed a pattern previously identified in songbirds (Silverin et al., 2000; Riters et al., 2001) with a much lower AA measured in the HPOA compared with the telencephalon.

Paired $t$ test revealed however no overall interhemispheric difference in AA measured in the three regions of interest. The inspection of individual data similarly did not reveal any systematic pattern of difference between hemispheres (Fig. 8). It must however be admitted that these enzymatic measures were obtained in brains collected in December when the lateralization of the BOLD response had a small amplitude. This result should thus be confirmed in future studies for brains collected at the peak of the reproductive season in March when a more pronounced lateralization of the BOLD response was detected.

\section{Discussion}

We demonstrate here that estrogen depletion within minutes alters auditory processing in male starlings as measured by fMRI. The BOLD response to auditory stimuli before and after VOR was much larger (both in amplitude and topography) in March than in December or May/June. Strikingly, these responses were lateralized to the left side and this lateralization was most pronounced in March. We also show that estrogen production specifically modulates selectivity for behaviorally relevant vocalizations in caudal NCM. These find- 


\section{Individual song > Species-specific songs}

\section{Control}
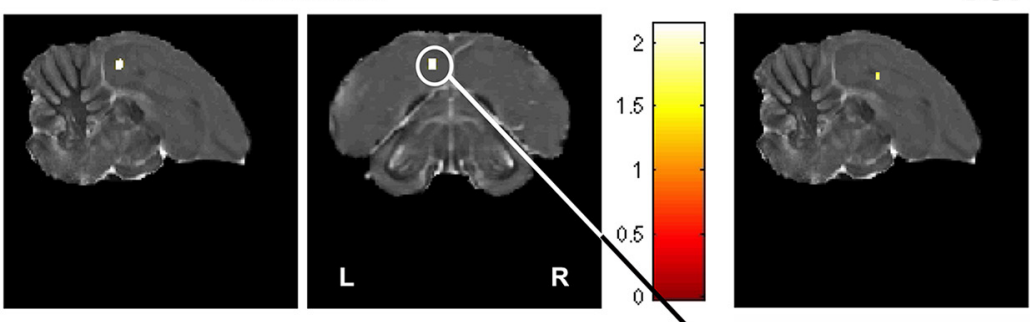

\section{Vorozole}
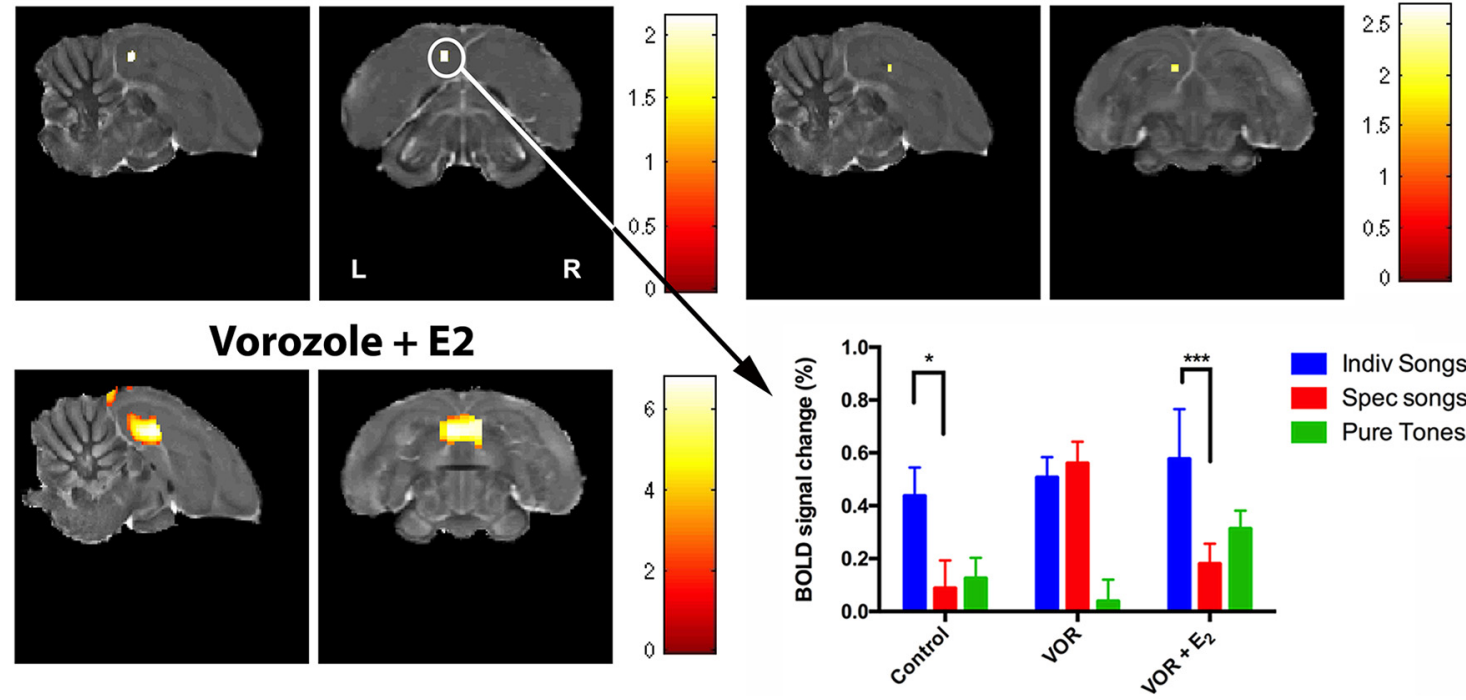

Figure 7. Statistical maps of regions displaying a significant difference in response to INDIV versus SPEC songs ( $t$ test) during different treatments. $t$ Values are color-coded according to the scale displayed on the right. Note the large individual song selectivity over both left and right NCM when E2 is administered. Bar graphs: relative response amplitude (+ SEM) of neural activations elicited by the different song stimuli in left caudal NCM (values from the voxel with the maximum $t$ value in control). Zero level corresponds to mean activation during rest periods. Stars indicate significant differences between INDIV and SPEC-specific songs $\left({ }^{*} p<0.05,{ }^{* * *} p<0.001\right)$.

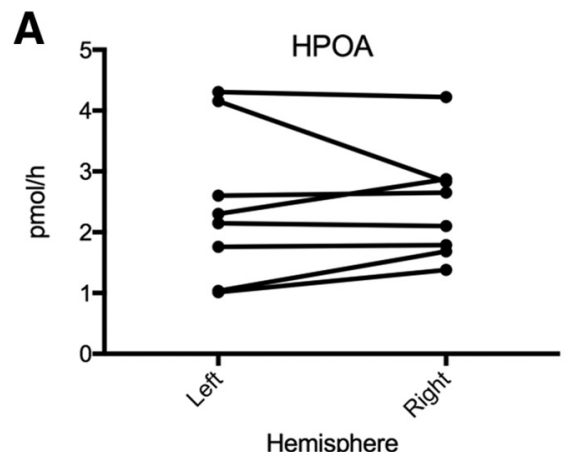

Hemisphere

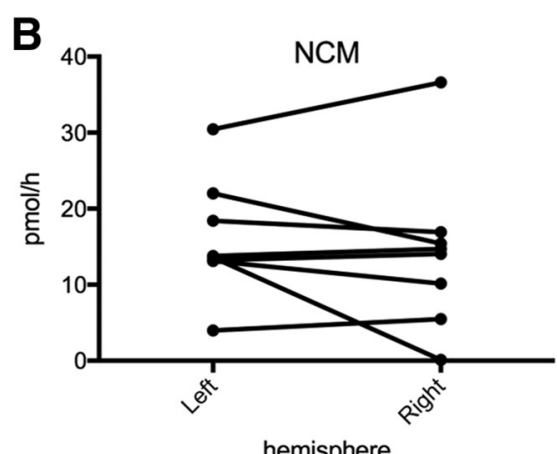

hemisphere

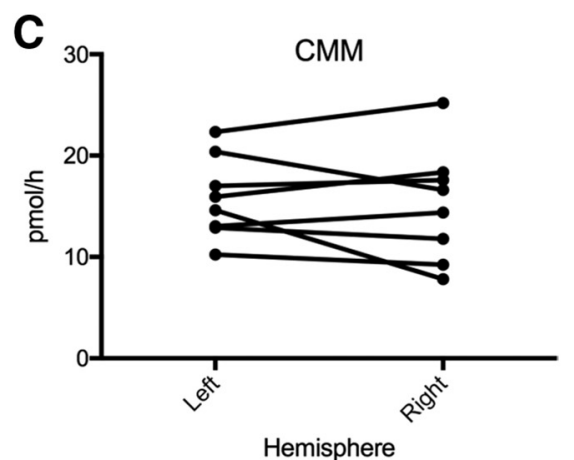

Hemisphere

Figure 8. Aromatase activity does not differ between hemispheres in the (A) HPOA, (B) NCM, and (C) CMM.

ings confirm and extend previous conclusions from electrophysiological studies.

Acute effects of aromatase inhibition

Acute changes in brain estrogen synthesis have been associated with acute behavioral changes in multiple vertebrate species. Here we show that the acute aromatase inhibition, resulting in a rapid decrease in estrogen production and thus availability, triggers rapid and marked effects on BOLD responses to conspecific songs in auditory regions. Importantly these acute changes differentially affect rostral versus caudal NCM as a function of seasons, with a major inhibition of the BOLD response by VOR in the caudal NCM in March but not in December or in May/June. Quite interestingly, this region (revealed by the season $\times$ treatment interaction) seems to correspond in parasagittal view to the region densely expressing aromatase in zebra finches (Pinaud et al., 2006) and black redstarts, Phoenicurus ochuros (Apfelbeck et al., 2013).

Importantly, BOLD response changes were observed within $10-45$ min after a single VOR injection thus confirming the rapid changes in neuronal activity induced by aromatase inhibition in the zebra finch NCM (Remage-Healey et al., 2010; Tremere and Pinaud, 2011). Classically, estrogens act by binding to nuclear receptors and inducing changes in transcription but this mode of action takes time (hours to days). Effects observed here seem too fast to depend on transcriptional effects and presumably result from another mode of action based on the binding of E2 to membrane estrogen receptors as supported by the finding that the fast cellular effects of E2 in the auditory zebra finch brain are mimicked by membrane impermeable estrogens (Remage-Healey et al., 2012). Vorozole presumably decrease in a rapid manner these membrane-initiated actions of E2 by suppressing the production of this steroid.

Moreover, as opposed to electrophysiological studies, the present $\mathrm{fMRI}$ studies allow us to precisely define the brain areas where changes in auditory processing occur. All secondary auditory brain regions are concerned. Note however that the season $X$ treatment interaction only concerned the caudal NCM suggesting that estrogen effects might be preferentially located in this subregion that displays a high aromatase expression and rapid fluctuations of E2 concentrations (Remage-Healey et al., 2012). 
Lateralization of effects

The lateralization of VOR effects on auditory responses is reminiscent of behavioral findings in zebra finches where localized aromatase inhibition in the left but not right NCM decreased behavioral preference for the bird's own song (Remage-Healey et al., 2010). These findings add to a growing literature showing left hemisphere dominance in auditory function in various species as demonstrated by BOLD responses (Poirier et al., 2009), ZENK expression (Avey et al., 2005; Moorman et al., 2012), electrophysiological recordings (George et al., 2004; Phan and Vicario, 2010), neurogenesis (Tsoi et al., 2014) and behavioral tests (RemageHealey et al., 2010).

Several mechanisms could explain this lateralization, including obviously a higher AA in the left than right auditory regions but this interpretation is not supported by the present AA assays showing no systematic interhemispheric difference (Fig. 8). It is however possible that rapid changes in AA triggered by activitydependent phosphorylations of the enzyme (Charlier et al., 2015) are lateralized and could thus result in a lateralized response to VOR.

Any other aspect of estrogen action (density of membrane estrogen receptors, their association with G-protein-coupled receptors or any subsequent signaling cascade) could be lateralized and differentially affected by estrogen depletion. Interestingly, a left-hemisphere dominance was recently suggested in the catecholaminergic innervation [tyrosine hydroxylase $(\mathrm{TH}) \mathrm{immu}-$ noreactivity] of auditory regions in white-throated sparrows, Zonotrichia albicollis (Matragrano et al., 2011). In the rat striatum, E2 rapidly affects TH phosphorylation resulting in a rapid increase in dopamine synthesis (Pasqualini et al., 1995). Since catecholamines control auditory activity (Appeltants et al., 2002; LeBlanc et al., 2007; Velho et al., 2012), a rapid decrease in estrogen availability following acute aromatase blockade could thus differentially affect auditory activity in the left and right hemispheres based on their differential innervation by $\mathrm{TH}$ and this in a season-dependent manner because chronic E2 also increases TH innervation (Matragrano et al., 2011).

\section{Effects of exogenous estrogens}

In general, E2 effects were in the opposite direction of VOR effects but no reversal by E2 injection was detected when considering the stimulus by treatment interaction (Fig. 6). This might be explained by the fact that E2 effects were tested in May/June when VOR effects had a small amplitude. Also, VOR specifically inhibits estrogen action at sites (synaptic terminals; Saldanha et al., 2011) where active aromatase is located, whereas exogenous E2 could potentially act on all sites expressing estrogen receptors.

\section{Stimulus specificity in the response to aromatase inhibition}

Manipulations of E2 bioavailability also differentially affected the auditory BOLD responses to specific stimuli (SPEC $>$ INDIV $>$ PT) showing here a clear reversal of VOR effect by treatment with exogenous E2 (Fig. 7). We had previously identified similar differences between birds studied during and outside the breeding season (De Groof et al., 2013). Our study suggests that these seasonal changes might reflect changes in neuroestrogen bioavailability so that estrogens would enhance auditory responses to relevant stimuli during the breeding season.

\section{Seasonal differences in response to aromatase inhibition}

Intriguingly very substantial differences in BOLD responses were observed after aromatase blockade in different seasons. These differences could reflect seasonal changes in aromatase expression and activity given that aromatase mRNA expression in ca- nary NCM (Serinus canaria; Fusani et al., 2000) or aromatase activity in song sparrows (Soma et al., 2003) are higher during the breeding season.

Similarly starling telencephalic AA is highest in March during the breeding season (Riters et al., 2001). However, birds were always treated with $\mathrm{T}$ to put them in supposedly similar endocrine conditions before imaging (Dawson and Howe, 1983; Ball and Wingfield, 1987). Exogenous T upregulates aromatase expression and activity in the canary NCM (Fusani et al., 2001). Yet in starlings annual changes of telencephalic AA correlate poorly with changes in plasma T (AA peaks 1 month before the T maximum; Riters et al., 2001) and no effect of T on AA was reported in the nidopallium of castrated zebra finches (Vockel et al., 1990). Whether T pretreatment increased AA in NCM to a similar high level before each imaging session thus remains uncertain.

Other factors, such as the photoperiodic state of the birds, might be involved in the control of telencephalic AA and responses to its inhibition. In December starlings were photosensitive. In March they had been exposed to increasing photoperiods for 3 months and were thus mildly photostimulated (exposed to $11 \mathrm{~h}$ light/13 h dark). Their status in May/June is not absolutely sure but they were probably photorefractory since they had been exposed to days longer than $12 \mathrm{~h}$ for $\sim 3$ months and were at that time exposed to $16 \mathrm{~h}$ light $/ 8 \mathrm{~h}$ dark. Under natural photoperiods such as mimicked here, starlings become photorefractory in May (Dawson, 2013). These changes in photoperiodic state could have induced changes in aromatase or in any other aspects of estrogen action (e.g., changes in catecholaminergic activity; see above) independent of the stimulation by exogenous $\mathrm{T}$. The volume of song control nuclei in American tree sparrows, Spizella arborea, for example increases in photostimulated males even if they are castrated (Bernard et al., 1997). Similarly, long days increase the volume of song control nuclei even in castrated starlings and this effect is blocked by melatonin (Bentley et al., 1999). Because melatonin is secreted during the dark phase of the cycle (Cassone, 1990), melatonin might play a key role in the seasonal changes of song control nuclei and more generally brain plasticity independent of T. This hormone, or other transmitter systems, might thus be causally implicated in the differential auditory-induced BOLD response observed after aromatase inhibition at different seasons.

Photoperiodic state might also control T or E2 action: exogenous $\mathrm{T}$ increases the volume of song control nuclei in photosensitive and photorefractory female starlings but singing frequency was increased only in photosensitive females (Rouse et al., 2015). Similarly, E2 effects on the latency to learn and respond to male conspecific song segments are modulated by photoperiod in male starlings (Calisi et al., 2013). Habituation or sensory adaptation (Chew et al., 1995; Stripling et al., 2001) could have occurred in this longitudinal study, however we have not seen any form of habituation in the BOLD response (data not shown) of starlings within one season and therefore think that habituation on a larger scale (between measurements) is unlikely. More work would be needed to identify the origins of the seasonal changes in BOLD response identified here.

In conclusion, the present study demonstrates that manipulations of estrogens bioavailability via acute injection of an aromatase inhibitor or of E2 markedly affect auditory-induced BOLD responses in a manner that is specific to the brain region and hemisphere considered, the type of auditory stimulus and the season. These findings confirm and markedly extend previous electrophysiological findings in zebra finches by identifying the neuroanatomical extension of the effects and demonstrating that 
they concern huge numbers of neurons in the areas of interest since many neurons in a voxel must be affected to generate a detectable change in BOLD signal. They provide a new extremely powerful tool to investigate auditory responsiveness in songbirds and its fast modulation by sex steroids.

\section{References}

Alward BA, de Bournonville C, Chan TT, Balthazart J, Cornil CA, Ball GF (2016) Aromatase inhibition rapidly affects in a reversible manner distinct features of birdsong. Sci Rep 6:32344. CrossRef Medline

Apfelbeck B, Mortega K, Kiefer S, Kipper S, Vellema M, Villavicencio CP, Gahr M, Goymann W (2013) Associated and disassociated patterns in hormones, song, behavior and brain receptor expression between lifecycle stages in male black redstarts, Phoenicurus ochruros. Gen Comp Endocrinol 184:93-102. CrossRef Medline

Appeltants D, Del Negro C, Balthazart J (2002) Noradrenergic control of auditory information processing in female canaries. Behav Brain Res 133: 221-235. CrossRef Medline

Avey MT, Phillmore LS, MacDougall-Shackleton SA (2005) Immediate early gene expression following exposure to acoustic and visual components of courtship in zebra finches. Behav Brain Res 165:247-253. CrossRef Medline

Ball GF, Wingfield JC (1987) Changes in plasma levels of sex steroids in relation to multiple broodedness and nest site density in male starlings. PhysiolZool 60:191-196.

Bentley GE, Van't Hof TJ, Ball GF (1999) Seasonal neuroplasticity in the songbird telencephalon: a role for melatonin. Proc Natl Acad Sci U S A 96:4674-4679. CrossRef Medline

Bernard DJ, Wilson FE, Ball GF (1997) Testis-dependent and -independent effects of photoperiod on volumes of song control nuclei in American tree sparrows (Spizella arborea). Brain Res 760:163-169. CrossRef Medline

Calisi RM, Knudsen DP, Krause JS, Wingfield JC, Gentner TQ (2013) Estradiol differentially affects auditory recognition and learning according to photoperiodic state in the adult male songbird, European starling (Sturnus vulgaris). PeerJ 1:e150. CrossRef Medline

Caras ML (2013) Estrogenic modulation of auditory processing: a vertebrate comparison. Front Neuroendocrinol 34:285-299. CrossRef Medline

Cassone VM (1990) Effects of melatonin on vertebrate circadian systems. Trends Neurosci 13:457-464. CrossRef Medline

Charlier TD, Cornil CA, Patte-Mensah C, Meyer L, Mensah-Nyagan AG, Balthazart J (2015) Local modulation of steroid action: rapid control of enzymatic activity. Front Neurosci 9:83. CrossRef Medline

Chew SJ, Mello C, Nottebohm F, Jarvis E, Vicario DS (1995) Decrements in auditory responses to a repeated conspecific song are long-lasting and require 2 periods of protein-synthesis in the songbird forebrain. Proc Natl Acad Sci U S A 92:3406-3410. CrossRef Medline

Cornil CA, Ball GF, Balthazart J (2006a) Functional significance of the rapid regulation of brain estrogen action: where do the estrogens come from? Brain Res 1126:2-26. CrossRef Medline

Cornil CA, Taziaux M, Baillien M, Ball GF, Balthazart J (2006b) Rapid effects of aromatase inhibition on male reproductive behaviors in Japanese quail. Horm Behav 49:45-67. CrossRef Medline

Cornil CA, Ball GF, Balthazart J, Charlier TD (2011) Organizing effects of sex steroids on brain aromatase activity in quail. PLoS One 6:e19196. CrossRef Medline

Cornil CA, Ball GF, Balthazart J (2012) Rapid control of male typical behaviors by brain-derived estrogens. Front Neuroendocrinol 33:425-446. CrossRef Medline

Dawson A (2013) The effect of latitude on photoperiodic control of gonadal maturation, regression and molt in birds. Gen Comp Endocrinol 190: 129-133. CrossRef Medline

Dawson A, Howe PD (1983) Plasma corticosterone in wild starlings (Sturnus vulgaris) immediately following capture and in relation to body weight during the annual cycle. General and comparative endocrinology 51:303-308. CrossRef Medline

De Groof G, Poirier C, George I, Hausberger M, Van der Linden A (2013) Functional changes between seasons in the male songbird auditory forebrain. Front Behav Neurosci 7:196. CrossRef Medline

De Groof G, George I, Touj S, Stacho M, Jonckers E, Cousillas H, Hausberger M, Güntürkün O, Van der Linden A (2016) A three-dimensional digital atlas of the starling brain. Brain Struct Funct 221:1899-1909. CrossRef Medline
De Ridder E, Pinxten R, Mees V, Eens M (2002) Short- and long-term effects of male-like concentrations of testosterone on female European starlings (Sturnus vulgaris). Auk 119:487-497.

Etgen AM, Pfaff DW (2010) Molecular mechanisms of hormone actions on behavior. Academic.

Fusani L, Van't Hof T, Hutchison JB, Gahr M (2000) Seasonal expression of androgen receptors, estrogen receptors, and aromatase in the canary brain in relation to circulating androgens and estrogens. J Neurobiol 43:254-268. CrossRef Medline

Fusani L, Hutchison JB, Gahr M (2001) Testosterone regulates the activity and expression of aromatase in the canary neostriatum. J Neurobiol 49: 1-8. CrossRef Medline

George I, Vernier B, Richard JP, Hausberger M, Cousillas H (2004) Hemispheric specialization in the primary auditory area of awake and anesthetized starlings (Sturnus vulgaris). Behav Neurosci 118:597-610. CrossRef Medline

Hausberger M, Forasté MA, Richard-Yris CN (1997) Differential response of female starlings to shared and nonshared song types. Etologia 5:31-38.

Heimovics SA, Prior NH, Maddison CJ, Soma KK (2012) Rapid and widespread effects of $17 \beta$-estradiol on intracellular signaling in the male songbird brain: a seasonal comparison. Endocrinology 153:1364-1376. CrossRef Medline

Heimovics SA, Ferris JK, Soma KK (2015) Non-invasive administration of $17 \beta$ estradiol rapidly increases aggressive behavior in non-breeding, but not breeding, male song sparrows. Horm Behav 69:31-38. CrossRef Medline

Kelly MJ, Rønnekleiv OK (2009) Control of CNS neuronal excitability by estrogens via membrane-initiated signaling. Mol Cell Endocrinol 308:1725. CrossRef Medline

LeBlanc MM, Goode CT, MacDougall-Shackleton EA, Maney DL (2007) Estradiol modulates brainstem catecholaminergic cell groups and projections to the auditory forebrain in a female songbird. Brain Res 1171:93103. CrossRef Medline

Maggi A, Ciana P, Belcredito S, Vegeto E (2004) Estrogens in the nervous system: mechanisms and nonreproductive functions. Annu Rev Physiol 66:291-313. CrossRef Medline

Matragrano LL, Sanford SE, Salvante KG, Sockman KW, Maney DL (2011) Estradiol-dependent catecholaminergic innervation of auditory areas in a seasonally breeding songbird. Eur J Neurosci 34:416-425. CrossRef Medline

Moorman S, Gobes SM, Kuijpers M, Kerkhofs A, Zandbergen MA, Bolhuis JJ (2012) Human-like brain hemispheric dominance in birdsong learning. Proc Natl Acad Sci U S A 109:12782-12787. CrossRef Medline

Pasqualini C, Olivier V, Guibert B, Frain O, Leviel V (1995) Acute stimulatory effect of estradiol on striatal dopamine synthesis. J Neurochem 65 : 1651-1657. Medline

Phan ML, Vicario DS (2010) Hemispheric differences in processing of vocalizations depend on early experience. Proc Natl Acad Sci U S A 107: 2301-2306. CrossRef Medline

Pinaud R, Fortes AF, Lovell P, Mello CV (2006) Calbindin-positive neurons reveal a sexual dimorphism within the songbird analogue of the mammalian auditory cortex. J Neurobiol 66:182-195. CrossRef Medline

Poirier C, Boumans T, Verhoye M, Balthazart J, Van der Linden A (2009) Own-song recognition in the songbird auditory pathway: selectivity and lateralization. J Neurosci 29:2252-2258. CrossRef Medline

Remage-Healey L (2014) Frank beach award winner: steroids as neuromodulators of brain circuits and behavior. Horm Behav 66:552-560. CrossRef Medline

Remage-Healey L, Joshi NR (2012) Changing neuroestrogens within the auditory forebrain rapidly transform stimulus selectivity in a downstream sensorimotor nucleus. J Neurosci 32:8231-8241. CrossRef Medline

Remage-Healey L, Maidment NT, Schlinger BA (2008) Forebrain steroid levels fluctuate rapidly during social interactions. Nat Neurosci 11:13271334. CrossRef Medline

Remage-Healey L, Coleman MJ, Oyama RK, Schlinger BA (2010) Brain estrogens rapidly strengthen auditory encoding and guide song preference in a songbird. Proc Natl Acad Sci U S A 107:3852-3857. CrossRef Medline

Remage-Healey L, Dong SM, Chao A, Schlinger BA (2012) Sex-specific, rapid neuroestrogen fluctuations and neurophysiological actions in the songbird auditory forebrain. J Neurophysiol 107:1621-1631. CrossRef Medline

Remage-Healey L, Jeon SD, Joshi NR (2013) Recent evidence for rapid syn- 
thesis and action of estrogens during auditory processing in a songbird. J Neuroendocrinol 25:1024-1031. CrossRef Medline

Riters LV, Baillien M, Eens M, Pinxten R, Foidart A, Ball GF, Balthazart J (2001) Seasonal variation in androgen-metabolizing enzymes in the diencephalon and telencephalon of the male European starling (Sturnus vulgaris). J Neuroendocrinol 13:985-997. Medline

Rouse ML Jr, Stevenson TJ, Fortune ES, Ball GF (2015) Reproductive state modulates testosterone-induced singing in adult female European starlings (Sturnus vulgaris). Horm Behav 72:78-87. CrossRef Medline

Saldanha CJ, Remage-Healey L, Schlinger BA (2011) Synaptocrine signaling: steroid synthesis and action at the synapse. Endocr Rev 32:532-549. CrossRef Medline

Silverin B, Baillien M, Foidart A, Balthazart J (2000) Distribution of aromatase activity in the brain and peripheral tissues of passerine and nonpasserine avian species. Gen Comp Endocrinol 117:34-53 CrossRef Medline

Soma KK, Schlinger BA, Wingfield JC, Saldanha CJ (2003) Brain aromatase, 5 alpha-reductase, and 5 beta-reductase change seasonally in wild male song sparrows: relationship to aggressive and sexual behavior. J Neurobiol 56:209-221. CrossRef Medline

Stokes TM, Leonard CM, Nottebohm F (1974) The telencephalon, diencephalon, and mesencephalon of the canary, Serinus canaria, in stereotaxic coordinates. J Comp Neurol 156:337-374. CrossRef Medline

Stripling R, Kruse AA, Clayton DF (2001) Development of song responses in the zebra finch caudomedial neostriatum: role of genomic and electrophysiological activities. J Neurobiol 48:163-180. CrossRef Medline

Trainor BC, Finy MS, Nelson RJ (2008) Rapid effects of estradiol on male aggression depend on photoperiod in reproductively non-responsive mice. Horm Behav 53:192-199. CrossRef Medline

Tremere LA, Pinaud R (2011) Brain-generated estradiol drives long-term optimization of auditory coding to enhance the discrimination of communication signals. J Neurosci 31:3271-3289. CrossRef Medline

Tremere LA, Jeong JK, Pinaud R (2009) Estradiol shapes auditory processing in the adult brain by regulating inhibitory transmission and plasticityassociated gene expression. J Neurosci 29:5949-5963. CrossRef Medline

Tsoi SC, Aiya UV, Wasner KD, Phan ML, Pytte CL, Vicario DS (2014) Hemispheric asymmetry in new neurons in adulthood is associated with vocal learning and auditory memory. PLoS One 9:e108929. CrossRef Medline

Van Meir V, Boumans T, De Groof G, Van Audekerke J, Smolders A, Scheunders P, Sijbers J, Verhoye M, Balthazart J, Van der Linden A (2005) Spatiotemporal properties of the BOLD response in the songbirds' auditory circuit during a variety of listening tasks. Neuroimage 25:1242-1255. CrossRef Medline

Velho TA, Lu K, Ribeiro S, Pinaud R, Vicario D, Mello CV (2012) Noradrenergic control of gene expression and long-term neuronal adaptation evoked by learned vocalizations in songbirds. PLoS ONE 7:e36276. CrossRef Medline

Vockel A, Pröve E, Balthazart J (1990) Effects of castration and testosterone treatment on the activity of testosterone-metabolizing enzymes in the brain of male and female zebra finches. J Neurobiol 21:808-825. CrossRef Medline 